\title{
Estimation of Sea Level Rise on the West African Coasts: Case of Senegal, Mauritania and Cape Verde
}

\author{
Cheikh Ahmed Tidiane Sarr ${ }^{1}$, Mouhamadou Moustapha Mbacké Ndour ${ }^{1 *}$, \\ Mahdi Haddad', Issa Sakho ${ }^{3,4}$ \\ ${ }^{1}$ Unite de Formation et de Recherches-Sciences de l'Ingénieur, Université of Thiès, Thiès, Senegal \\ ${ }^{2}$ Agence Spatiale ALgérienne, Centre des Techniques Spatiales, Arzew, Oran, Algérie \\ ${ }^{3}$ Université Amadou Mahtar Mbow de Dakar, Dakar, Senegal \\ ${ }^{4}$ UMR CNRS 6143 M2C, Normandie Université, Mont-Saint-Aignan, France \\ Email: *moustapha.ndour@univ-thies.sn
}

How to cite this paper: Sarr, C.A.T., Ndour, M.M.M., Haddad, M. and Sakho, I. (2021) Estimation of Sea Level Rise on the West African Coasts: Case of Senegal, Mauritania and Cape Verde. International Journal of Geosciences, 12, 121-137.

https://doi.org/10.4236/iig.2021.122008

Received: January 6, 2021

Accepted: February 19, 2021

Published: February 22, 2021

Copyright $\odot 2021$ by author(s) and Scientific Research Publishing Inc. This work is licensed under the Creative Commons Attribution International License (CC BY 4.0).

http://creativecommons.org/licenses/by/4.0/

\begin{abstract}
The advent of technology in the world has led to enormous, varying economic and social changes. Those changes have influenced the climate balance, which leads to global temperature rise, hence oceanic expansion and melting glaciers. These various phenomena caused the variation in the mean sea level. Thus, in this study we have evaluated that variation from the instrumental recordings of the tide gauges available in the region, which led us to choose the tide gauges of Dakar (Senegal), Nouakchott (Mauritania) and Palmeira (Cape Verde). The analysis of the tidal series began with the test of presence or absence of significant trends in the series using the Man-Kendall method followed by the decomposition of these series using the SSA, ARIMA and SLT techniques, which would result in the trend, seasonality and residues. The results of this analysis show a variation of $1.52 \mathrm{~mm} /$ year, $4.51 \mathrm{~mm} /$ year and $20.08 \mathrm{~mm} /$ year respectively for the Dakar, Palmeira and Nouakchott tide gauges.
\end{abstract}

\section{Keywords}

Sea Level, Trend Analysis, Senegal, Palmeira, Nouakchott

\section{Introduction}

The sea level has changed on various time scales. During the last ice age, around 20,000 years ago, the sea level was on average $120 \mathrm{~m}$ lower than today. With the melting of the ice caps that then covered northern America and Europe, the 
world's fastest sea level rise occurred at an average rate of around $10 \mathrm{~mm} /$ year between 15,000 and 6000 years before our era [1].

According to geological data, eustatic sea level rise has subsequently occurred at an average rate of $0.5 \mathrm{~mm}$ per year for the past 6000 years, and 0.1 to $0.2 \mathrm{~mm}$ per year for the past 3000 years. This rate is about 10 times lower than that observed in the 20th century. During the last 1000 years and before the $20^{\text {th }}$ century, the rate of change in sea level would have been less than $0.2 \mathrm{~mm} /$ year [2] [3].

While for 1000 years the sea level has changed little, observations made from core samples and tide gauge measurements show us that at the level of modern man, the rise in sea level has significantly started over the last century. Indeed, for the improvement of living conditions, developed countries used energy resources for their industrialization at the end of the $19^{\text {th }}$ century [4] [5]. The use of such resources has led to the emission of greenhouse gases which indirectly affect the sea level by warming our planet.

While the mean sea level has risen very little over the past 1000 years, recent analyses using measurements from historical tide gauges indicate a much higher global sea level rise, of around 1.5 to $2 \mathrm{~mm}$ /year for the $20^{\text {th }}$ century [6]. That increase, which is 10 times greater than (those) in previous centuries, is subject to considerable interest in the current context of global warming observed in recent decades. Since the end of 1992, spatial altimetry has also provided absolute (geocentric) measurements of the global mean level of the oceans, on a continuous basis, calculated from the altimetric data. Recent estimates based on the latter measurement technique show a sea level rise of $3.1 \pm 0.4 \mathrm{~mm} /$ year between November 1992 and January 2018 [7]. The reasons for this rise result from two major processes [8]: the thermal expansion of the ocean caused by variations in the thermal content of the ocean and the inflow of fresh water into the ocean caused by the melting of the polar caps and mountain glaciers, as well as potential exchanges with continental water reservoirs (climatic and anthropogenic effects).

On average over the period 1993-2017, the warming of the oceans in the sea level balance is $42 \%$. The rate of average sea level rise due to thermal expansion was estimated at $1.3 \pm 0.4 \mathrm{~mm} /$ year between 1993 and 2017. The contribution of continental glaciers and ice caps (Greenland and Antarctica) between 1993 and 2011 has roughly the same contribution in the sea level balance, at $21 \%$ and $23 \%$, respectively. The average contribution of continental glaciers and the two polar caps was $0.65 \pm 0.15 \mathrm{~mm} /$ year between 1993 and 2017. The contribution of ice caps for the same period is $0.73 \pm 0.10 \mathrm{~mm} /$ year. Inland waters have played little role in long-term sea level change over the past decades [8].

This rise in global sea level will have a lot of consequences for many populations living on the coasts. The physical phenomena linked to the rise in sea level in coastal areas fall into five categories: worsening of the submersion of low-lying coasts (deltas, coral reefs, some islands), acceleration of the erosion of beaches and cliffs, increased salinization of aquifers and surface water, greater amplitude 
of high water, and finally the effects of natural disasters such as storms and floods [9].

If the overall trend of mean level is increasing, regional causes are mainly due to large-scale changes in ocean density in response to forcing factors (e.g. wind forcing, heat exchange and freshwater at the air-sea interface) and their consequences in ocean circulation. Thus, the greater regional variabilities of the mean level are mainly due to changes in ocean temperature (i.e. from non-uniform thermal expansion), but in some regions variations in ocean salinity are also significant.

The main objective of this project relates to the study of the evolution of the local sea level on the West African coasts (Senegal, Mauritania and Cape Verde) where few scientific studies on this topic have been carried out. As such, specific objectives have been defined:

To objectively test whether the three tidal series recorded at the level of the three ports of Dakar (Senegal), Nouakchott (Mauritania) and Palmeira (Cape Verde) show or not significant monotonic trends upward or downward. The statistical test used is the Mann-Kendall nonparametric test which takes into account the presence of seasonality in the series; the case of tidal series.

To carry out a decomposition of the three series of measurements into a set of several independent components, such that each component in this sum can be identified as being the "trend" component, the "seasonality" component and the "noise" component. The trend component is used to determine the changes in sea level during the period considered. This trend will highlight the slow rise in mean sea level under the combined effect of thermal expansion due to steric effect, melting ice and glaciers, precipitation, etc. The seasonality component is used to determine the cycle of sea level variation, valid for the period covered by the series of tide measurements and from which the effects due to changes in the trend or in noise are eliminated. Among the various methods that produce reliable decompositions for large data sets, the most recommended and used ones in this study are: Singular Spectral Analysis (SSA), ARIMA and Seasonal-Trend Decomposition Based on Loess (STL).

The rest of this article is organized as follows: The "Tide data used" section presents the tide series considered in this study. The "Methodology" section introduces a pedagogical and exhaustive description of the approaches to analysis of tidal series. The results of detection or not of significant trends within tide gauge series as well as the results of decomposition of these series according to the different techniques (SSA, ARIMA and STL) are presented in the "Experimental results" section. Finally, the conclusions of this study are presented in the last section.

\section{Tide Data Used}

Tide gauges are the first instruments to measure variations in sea level. This measurement was taken in the $18^{\text {th }}$ century by simply reading the water level 
on a graduated scale located at certain ports. Mechanical tide gauges were then developed in the $19^{\text {th }}$ century, allowing automatic recording of the water heights measured by the tide gauge. The first mechanical instruments were float tide gauges. The measurement principle is based on the vertical displacement of a float in a tube, the stilling well, which mechanically filters out low wavelength oscillations from the water surface. The vertical movements of the float are plotted on a roll of paper which then provides an automatic recording of water heights as a function of time [10]. Since then, techniques have been considerably modernized: ultrasonic tide gauges measure the round trip propagation time of an acoustic wave emitted above the body of water, while pressure tide gauges measure the pressure exerted by the column of water above the submerged device. They are digital and remotely searchable instruments for data collection.

West Africa appears as the plunging hull in the Atlantic Ocean, despite this peculiarity it has the fewest tide gauges among the world's coasts. The tidal data used in this study (Dakar, Nouakchott and Palmeira) with a monthly resolution are those taken from the database of the global sea level observing system GLOSS (Global Sea Level Observing System).

GLOSS was established by the Intergovernmental Oceanographic Commission (IOC) of the United Nations Educational, Scientific and Cultural Organization (UNESCO) in 1985. GLOSS's main mission is to oversee and coordinate regional and global networks observation of sea level to support scientific research. In the course of its mission, we witness the creation of the CGN in 1990, made up of about 300 tide gauges spread all over the world and most of which are now operational (Figure 1). In 1997, the second GLOSS implementation plan incorporated tide gauges at a number of selected sites, mainly islands, for the calibration of altimeters (the GLOSS-ALT set) [11].

Dakar station: Dakar (Senegal) has one of the longest sea level records in Africa, with a multi-decadal time series. This station is maintained locally by the Phares et Balises sub-division of the Dakar Port Authority. The year 1902 was associated with the first measurements with the old Dakar tide gauge. The latter

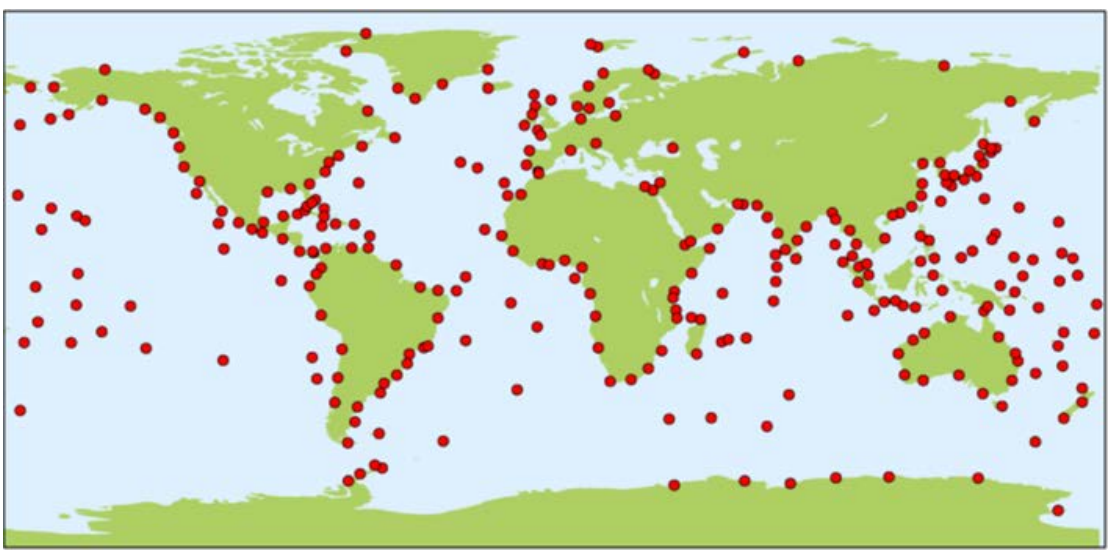

Figure 1. Geographical representation of GLOSS-GCN stations. 
operated for a period of less than eighteen years. It was not until 22 years, in 1942, that was experimented a second series of measurements with this tide gauge. This series, seen in 1966, were followed by a long period of absence [12]. Thus a new series has been updated since 1992 and will be subject to analysis in this study.

Palmeira resort: Cape Verde is an island state, made up of an archipelago of ten volcanic islands. The volcanic activity of these islands is explained by the presence of a hot spot associated with a bathymetric swell phenomenon, which would have formed these islands. Despite this volcanic activity, it was not until 2000 that a tide gauge was installed in Palmeira. The latter is located in the Atlantic Ocean, off the coast of Senegal.

Nouakchott station: The Autonomous Port of Nouakchott known as "Port de l'Amitié" has had a tide gauge installed at the western end of the quay since May 21,1999 . However, the data available for download is from 2008; this is because the Port de l'Amitié tide gauge is an OTT R 16 type vertical float limigraph. The recording was carried out directly on graph paper. Figure 2 represents the study area and the geographical location of the three tide stations (Dakar, Palmeira and Nouakchott). Figure 3 represents the three tidal series. Table 1 indicates for each tide gauge the geographical position, the range of data used, the percentage of existing data within the series and the rate of change in $\mathrm{mm} /$ year estimated by linear regression.

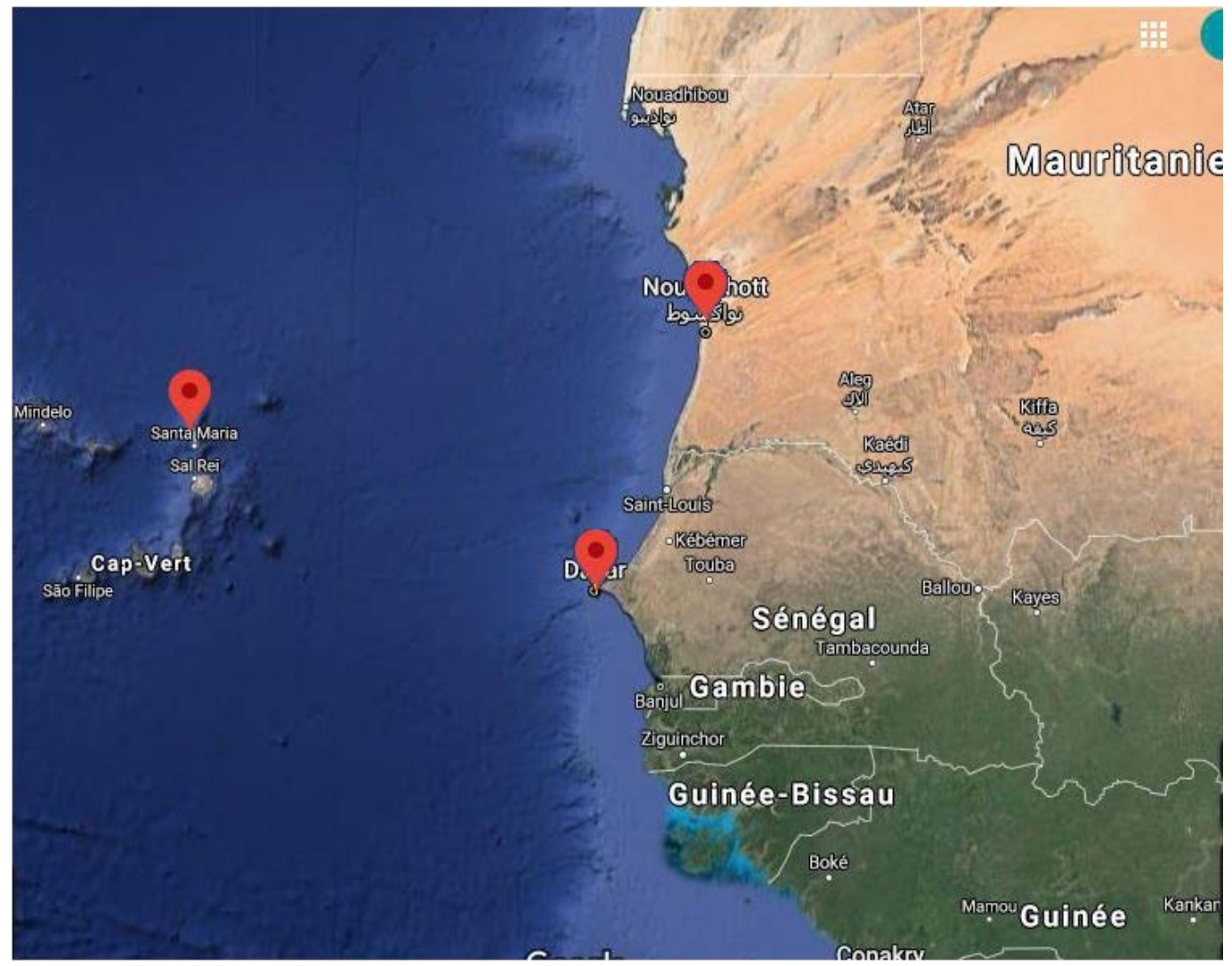

Figure 2. Geographic location of the Dakar, Nouakchott and Palmeira tide stations. 
(a) Dakar

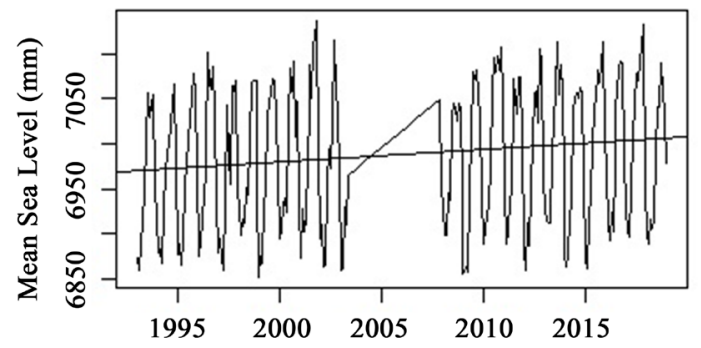

(b) Palmeira

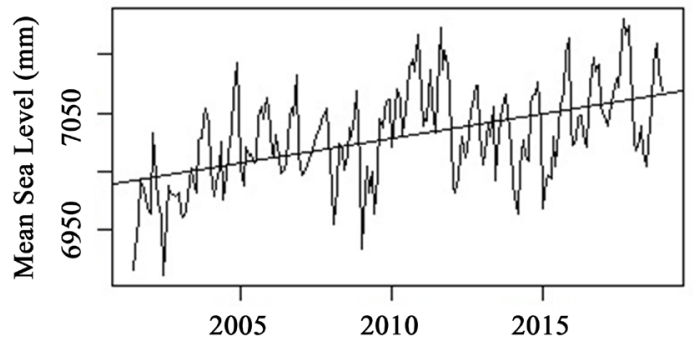

(c) Nouakchott

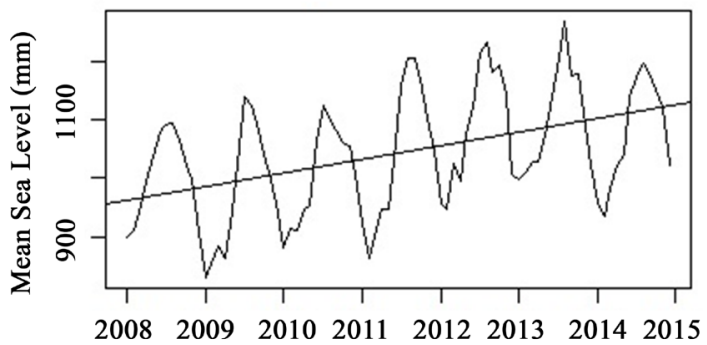

Figure 3. Tide gauge series. From top to bottom: (a) Dakar; (b) Palmeira and (c) Nouakchott.

Table 1. Descriptive statistics of tide data.

\begin{tabular}{cccccc}
\hline Station & $\begin{array}{c}\text { Latitude } \\
\left(^{\circ}\right)\end{array}$ & $\begin{array}{c}\text { Longitude } \\
\left(^{\circ}\right)\end{array}$ & Périod & $\begin{array}{c}\text { Obs. without } \\
\text { missing data }\end{array}$ & $\begin{array}{c}\text { Variation rate } \\
(\mathrm{mm} / \text { year })\end{array}$ \\
\hline Dakar & $14.683333 \mathrm{~N}$ & $17.416667 \mathrm{~W}$ & $1993-2018$ & $78.53 \%$ & $1.52 \pm 0.61$ \\
Palmeira & $16.750000 \mathrm{~N}$ & $22.983333 \mathrm{~W}$ & $2001-2018$ & $93.06 \%$ & $4.22 \pm 0.51$ \\
Nouakchott & $17.989556 \mathrm{~N}$ & $16.036958 \mathrm{~W}$ & $2008-2014$ & $90.48 \%$ & $24.94 \pm 5.64$ \\
\hline
\end{tabular}

\section{Methodology}

\subsection{Mann-Kendall Test}

The main goal of trend analysis is to find out, objectively, whether there is a significant systematic change in the time series or not. The Mann-Kendall trend test is a non-parametric test widely used to identify a trend in a series, even if there is a seasonal component in the series. This nonparametric trend test is the result of an improvement of the test studied first by [13] then taken up by [14] and finally optimized by [15] so as to take into account a seasonal component.

The Mann-Kendall non-parametric test is applicable to cases where the $X_{i} \mathrm{da}$ ta of a time series can be written in the following form 


$$
X_{i}=f\left(t_{i}\right)+\varepsilon_{i}
$$

where $f(t)$ is an increasing or decreasing monotonic continuous function. The residuals $\varepsilon_{i}$, with the same distribution, have a zero mean. The dispersion (or variance) of the distribution is stationary. The data can be annual, monthly, weekly... for a given site.

For a series that does not have a seasonal component, the Mann-Kendall $S$ statistic is calculated using the following formulation

$$
S=\sum_{k=1}^{n-1} \sum_{j=k+1}^{n} \operatorname{sgn}\left(x_{j}-x_{k}\right)
$$

$x_{j}$ and $x_{k}$ are the monthly values of months $j$ and $k$, with $j>k$, with the expectation $E(S)=0$, and

$$
\operatorname{sgn}(x)=\left\{\begin{array}{lr}
1 & \text { si } x>0 \\
0 & \text { si } x=0 \\
-1 & \text { si } x<0
\end{array}\right.
$$

The variance of $S$ is given by:

$$
\operatorname{Var}(S)=\frac{1}{18}\left\{n(n-1)(2 n+5)-\sum_{k=1}^{n} t_{k} k(k-1)(2 k+5)\right\}
$$

where $t_{k}$ represents the number of equalities (number of ties) involving $k$ values.

The value of $S$ and $\operatorname{Var}(S)$ are used to calculate the statistical test $Z$ and is written in the following form

$$
Z= \begin{cases}\frac{S-1}{\sqrt{\operatorname{Var}(S)}} & \text { si } S>0 \\ 0 & \text { si } S=0 \\ \frac{S+1}{\sqrt{\operatorname{Var}(S)}} & \text { si } S<0\end{cases}
$$

If the values of the series tend to increase (respectively fall) over time, $Z$ should be positive (respectively negative).

The probability value $p$ of the statistical test $S$ can be estimated using a cumulative normal distribution function:

$$
p=2\left[1-\frac{1}{\sqrt{2 \pi}} \int_{-\infty}^{|z|} \mathrm{e}^{\frac{-t^{2}}{2}} \mathrm{~d} t\right]
$$

Thus, if $p \leq 0.05$, then the local trend is statistically significant at the $5 \%$ risk threshold.

To take into account the seasonality of the data, we define $\operatorname{Var}(S)$ as

$$
\operatorname{Var}\left(S^{\prime}\right)=\sum_{i=1}^{12} \operatorname{Var}\left(S_{i}\right)=\frac{1}{18} \sum_{i=1}^{12} n_{i}\left(n_{i}-1\right)\left(2 n_{i}+5\right)-\sum_{t_{i}} t_{i}\left(t_{i}-1\right)\left(2 t_{i}+5\right)
$$

With:

$$
S_{i}=\sum_{k=1}^{n_{i}-1} \sum_{j=k+1}^{n_{i}} \operatorname{sgn}\left(x_{i j}-x_{i k}\right)
$$


where $x_{i j}$ and $x_{i k}$ are the values of month $i$ of year $j$ and $k$ with $j>k$. The sign sgn is calculated in the same way as in relation (2).

Using the normal approximation, $Z^{\prime}$ is defined as:

If $Z^{\prime}>0$, the trend is monotonic and increasing. Otherwise, it is decreasing monotonously

\subsection{Technical Decomposition}

\section{Singular Spectral Analysis-SSA}

Singular Spectral Analysis is a relatively recent technique that consists of breaking down a signal into periodic components, trend and noise. The main idea of SSA is to decompose into the sum of a reduced number of components thanks to the singular value decomposition (SVD) of a specific matrix built from the data ([16] [17] [18]). The SSA algorithm has two steps [18].

Decomposition: this first step corresponds to performing the SVD of a Hankel matrix called a "trajectory matrix". This is constructed by associating with a signal $S$ formed by $N$ samples $(K=N L+1)$ column vectors of dimension $L$, the $k^{\text {th }}$ vector being given by $s_{k}=\left(s_{k} s_{k+1} \cdots s_{k+L-1}\right)^{\mathrm{T}}$. The trajectory matrix (of dimension $L \times K)$ is then deduced by $\left[X=s_{1}: \cdots: s_{k}\right]$.

By SVD [8], this matrix of rank $r \leq L$ breaks down into $r$ elementary matrices $X_{i}$ of rank 1. Let $\sigma_{1}, \cdots, \sigma_{r}$ be the non-zero singular values of $X$ classified in decreasing order and $\left(U_{1}, V_{1}\right) ;\left(U_{r}, V_{r}\right)$ the associated left and right singular vectors ( $\sigma_{i}^{2}$ being the eigenvalue of the covariance matrix $C=X X^{\mathrm{T}}$ associated with the eigenvector $U_{i}$, with $V_{i}=X^{\mathrm{T}} U_{i} / \sigma_{i}^{2}, X$ is written:

$$
X=\sum_{i=1}^{r} X_{i}, \text { avec } X_{i}=\sigma_{i} U_{i} V_{i}^{\mathrm{T}}
$$

The ratio $\sigma_{i}^{2} / \sum_{i=1}^{d} \sigma_{i}^{2}$ represents the characteristic of the contribution of the matrix $X_{i}$.

Reconstruction: signals $X_{1}, \cdots, X_{r}$ of length $N$ are constructed by averaging the elements of the anti-diagonals of the matrices $X_{1}, \cdots, X_{r}$. A grouping into components is then carried out, generally referring to the analysis of the singular values and/or the behavior of the eigenvectors and/or the correlation rate between the $X_{i}$. This results in $m$ components $Y_{j}$, each being associated with a group $I_{j}$

$$
\mathcal{S}=\sum_{j=1}^{m} \mathcal{Y}_{j} \text { avec } \mathcal{Y}_{j}=\sum_{i \in I_{j}} \mathcal{X}_{i}
$$

This algorithm is thus particularly effective for identifying sinusoidal signals (possibly modulated in amplitude by an exponential) or polynomial functions of time, but these components must be clearly distinguished for this, which leads to the notion of separability within the meaning of the SSA.

\section{ARIMA}

ARIMA (Autoregressive Integrated Moving Average) [20] is a technique commonly used to fit time series data and to make forecasts. ARIMA models allow three types of temporal processes to be combined: autoregressive processes 
(AR-AutoRegressive), integrated processes (I-Integrated), and moving averages (MA-Moving Average). In the most general case, an ARIMA model combines the three types of random processes, the contribution of each of them being specified by the notation ARIMA $(p, d, q)$, where $p$ is the order of the autoregressive process AR $(p), d$ the degree of integration of a process I ( $d$ ), and $q$ the order of the moving average MA $(q)$.

From a practical point of view, the first parameter to choose is the degree of differentiation $d$. To do so, we first check the stationarity of the data. If the data is stationary, then $d=0$. If the data shows a trend, we take the first difference and check the stationarity again. We keep taking the differences until we get a stationary output. The number of difference required is the number $\mathrm{d}$. We can also calculate the empirical autocorrelations (autocorrelation function ACF) and analyze the rate of decrease towards 0 of this function. If this decrease is slow, we can suspect a non-stationarity. Note that in practice the case $d>2$ rarely happens. After determining $d$, we can use the partial auto correlation function (PACF) to obtain the order $p$. If the PACF stops after a few shifts, this number is the order of AR. Finally, the $q$ order of MA is determined by examining the autocorrelation $(\mathrm{ACF})$ of the differentiated data. If the ACF stops after a few shifts, this number is the order of MA

Seasonal-Trend Decomposition Based on Loess-STL

STL initially proposed by [21] and developed by [22] is a non-parametric method which, from an additive model, decomposes a time series $\left(Y_{t}\right)$ into three components: trend $\left(C_{t}\right)$, season $\left(S_{t}\right)$ and residues $\left(\varepsilon_{t}\right)$.

STL is an iterative procedure that uses weighted local regression functions, called LOcally wEighted regreSsion Smoother-LOESS. Each point $\left(x_{0}, y_{0}\right)$ in the dataset is replaced by a linear regression on the points $\left(x_{i}, y_{i}\right)$ of its neighborhood, assigned a weighting depending on the distance $\left|x_{i}-x_{0}\right|$ with respect to the point $\left(x_{0}, y_{0}\right)$. This is a nonparametric smoothing determined by the number of points participating in local regressions. The parameters to be defined are the size of the neighborhood and the degree of the polynomial for the adjustment function (constant, linear or quadratic).

Due to its ability to manage outliers or missing data in a time series, the Seasonal-Trend Decomposition Based on Loess-STL technique provides a reliable and robust estimate of trend and seasonality. Moreover, according to [23] and [24] its flexibility, simplicity and computing performance offer the possibility of easily processing a large volume of data

\section{Experimental Results}

\subsection{Trend Tests}

The results of this section relating to the Mann-Kendall trend test are obtained through the "trend" package [25] developed in the R environment. This package is a set of functions dedicated to the analysis of time series. The "trend" functions can be used as a basis for detecting trends, estimating rates of change, de- 
tecting break points, estimating partial correlations, etc.

In the case of the Mann-Kendall test with seasonality, the seasonality of the series is taken into account. In other words, for monthly data with a seasonality of 12 months, we will not seek to know if there is an overall growth over the series, but simply whwther from January to January, from February to the next, so on and so forth, there is a trend. The variance of the statistics can be calculated by assuming that the series are independent (for example the values for the months of January and the months of February are independent).

The results of the application of the Mann-Kendall test with seasonality on the three tide gauge series (Dakar, Palmeira and Nouakchott) are given in Table 2. The p-values calculated from one month to another are lower than the significance level $\alpha=0.05$. We therefore reject the null hypothesis H0 (There is no significant trend in the series for the twelve months, and we retain the alternative hypothesis $\mathrm{H} 1$ (There is a trend in the series). The three tide series present, from month to month, a significant monotonically increasing trend: $S^{\prime}>0$.

\subsection{Breakdown of Series}

The objective is to decompose the sea level series into a sum of series, such that each component in this sum can be identified as being the trend component, the seasonality component and the noise component.

The results of this section relating to the SSA analysis are obtained through the RSSA package [8] For a good use of RSSA, examples with code fragments under the $\mathrm{R}$ environment, dedicated to the explanation of the methodology, are presented in [26].

The width of the "covariance-lag L" window is the only parameter in the decomposition step of the SSA technique. According to [16], the covariance-lag acts as a window on the signal, it must be long enough to encompass the period of the sought signal (exactly as in Fourier spectral analysis...). On this recommendation, we have chosen for our application and for each tide gauge series $L$ close to $N / 2$ where $N$ is the dimension of the series. In our case, $L$ is taken equal to 144 for the Dakar series, 108 for the Palmeira series and 48 for the Nouakchott series.

In order to validate the quality of the SSA reconstruction of each sea level series, two further decompositions of the tidal series were performed using the ARIMA technique and the Seasonal-Trend Decomposition Based on Loess-STL

Table 2. Statistics of the Mann-Kendall test with seasonality for the three tide series. H_0: There is no trend in the series, $\mathrm{H}_{-} 1$ : There is a trend in the series.

\begin{tabular}{cccccc}
\hline Station & Périod & $\begin{array}{c}\text { Statistical } \\
\boldsymbol{S}^{\prime}\end{array}$ & $\operatorname{Var}(\boldsymbol{S})$ & $\begin{array}{c}\text { P-value of } \\
\text { the test }\end{array}$ & $\begin{array}{c}\text { The risk of rejecting the null } \\
\text { hypothesis (in\%) when it is true }\end{array}$ \\
\hline Dakar & $1993-2018$ & 6335 & $3,390,581.00$ & $<0.001$ & 0.06 \\
Palmeira & $2001-2018$ & 8042 & $1,050,963.00$ & $<0.0001$ & 0.00 \\
Nouakchott & $2008-2014$ & 1037 & $66,999.66$ & $<0.0001$ & 0.01 \\
\hline
\end{tabular}


procedure.

Regarding the decomposition by the ARIMA method, the different steps are implemented in the R programming environment by the functions: "diff" (for the differentiation), "acf" (for the calculation of the function autocorrelation) and "PACF" (partial autocorrelation function). The adjustment of the data according to the possible ARIMA $(p, d, q)$ models is done through the function "arima".

The best ARIMA adjustment model $(p, d, q)$ is selected among the different models according to the values of the Akaike information criterion (Akaike Information Criterion-AIC) and of the Bayesian information criterion (Bayesian Information Criterion-BIC). The idea is to choose a model with minimum AIC and BIC values. In our case, the ARIMA processes chosen are: ARIMA $(2,0,1)$ for the Dakar series, ARIMA $(0,1,1)$ for the Palmeira series and ARIMA $(0,1$, 1) for the series of Nouakchott. Finally, the breakdown of the series is done using the "ARIMAdec" function.

The STL technique, on the other hand, is implemented in the R programming environment by the "stl" function. This function returns an object of class STL comprising in particular a component called time series which is a multiple time series composed of columns called trend, seasonal and remainder, corresponding respectively to the trend, the seasonal effect and the remainder (residuals).

The decomposition results (SSA, Arima and STL) obtained for the three tidal series of Dakar, Palmeira and Nouakchott are represented by Figures 4-6, respectively. These figures reveal that the trends extracted by the use of the three techniques SSA, Arima and STL are quite similar (correlation coefficient, $r>0.9$ ) and clearly follow the main trend of the initial series (Figure 2). These trends confirm the rise in sea levels along the West African coast. Likewise, the (total) seasonality extracted is similar (correlation coefficient, $r>0.9$ ). The harmonic components show that the frequency of the seasonal signal is particularly strong. Its amplitude is around $200 \mathrm{~mm}$ for Dakar and Nouakchott and around $80 \mathrm{~mm}$ for Palmeira. The amplitude of the tailings signals is relatively small (around 60 $\mathrm{mm}$ for the three tide stations).

The tidal measurement is a measurement relating to the earth's crust. The observation of sea level by tide gauges is therefore affected by the vertical movement (in English, Vertical Land Motion-VLM) of the earth. The possible geological origins of this movement are diverse. The physical process affecting tide gauges and the best studied is certainly the postglacial rebound (glacial isostatic adjustment, GIA): it is the only geological process that can be modeled in a global way, even if large uncertainties remain. Successive models of [27] (latest: ICE-6G_C (VM5a), available from the University of Toronto website: site: www.atmosp.physics.utoronto.ca/ peltier/data.php) are most commonly used to correct tide gauge measurements of postglacial rebound. Such models are relatively reliable, but studies show that the estimated velocity values are still too sensitive to some parameters of the earth model, such as the thickness of the li- 
thosphere or the mantle viscosity, and therefore too uncertain [19].

Table 3 gives the sea level variation rates estimated by applying the linear regression method to the extracted trend components. The columns of this table indicate: the station, the contribution of the trend component in the initial series, the rate of change of the trend component estimated in $\mathrm{mm} / \mathrm{year}$ and the standard error (SSA, Arima and STL), the correction due vertical movements of the earth's crust (VLM) according to the ICE-6G_C model (VM5a) and the corrected rate of change of VLM (Arima). As can be seen in column 8 of Table 3, all series of tide measurements show increasing rates of change. The highest trend estimated at the Nouakchott station at $20.08 \mathrm{~mm} /$ year could be due to a high local subsidence rate.
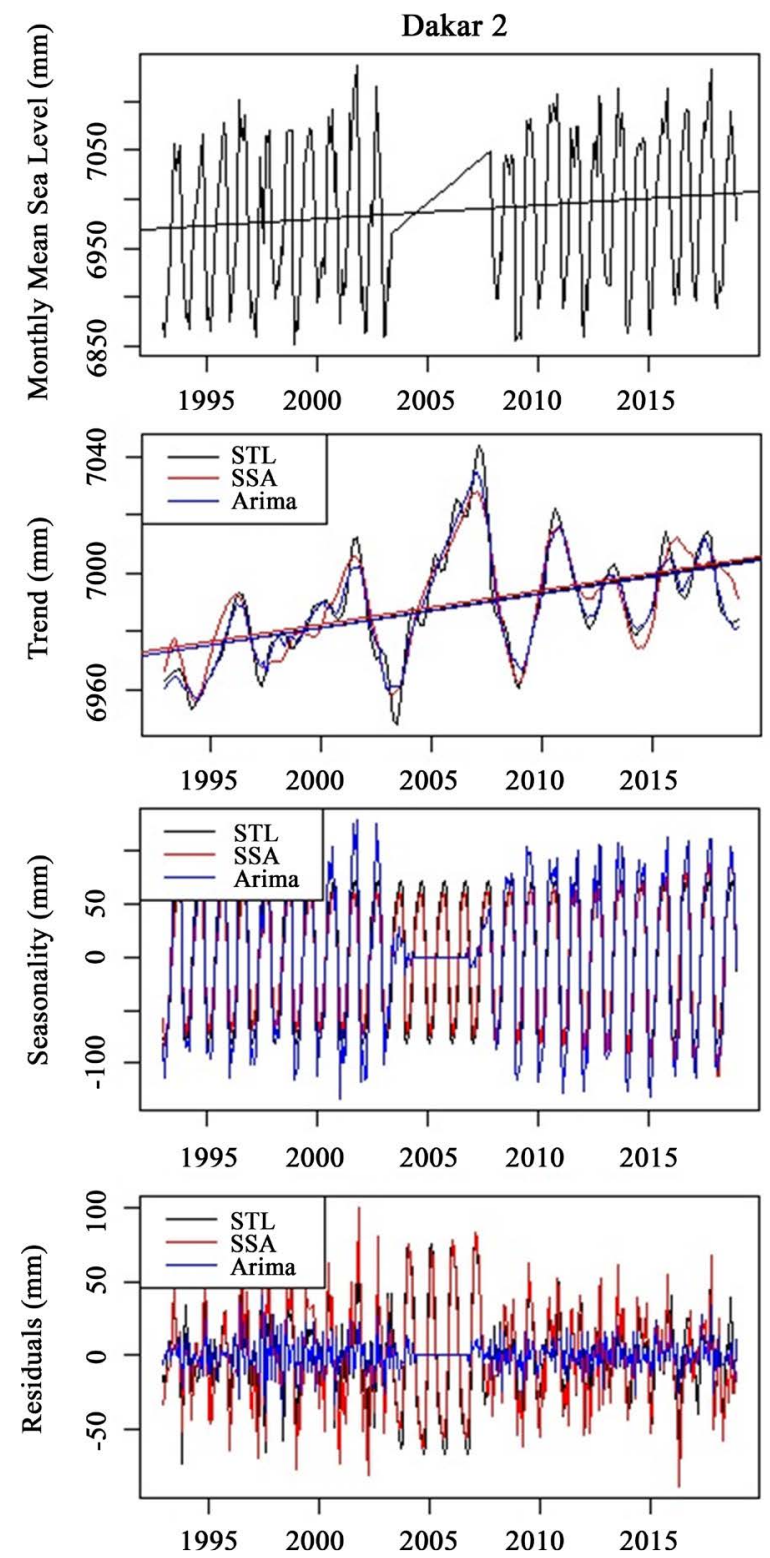

Figure 4. Results of the decomposition of the Dakar tide gauge series. In red: SSA, in blue; Arima and in black: STL. 

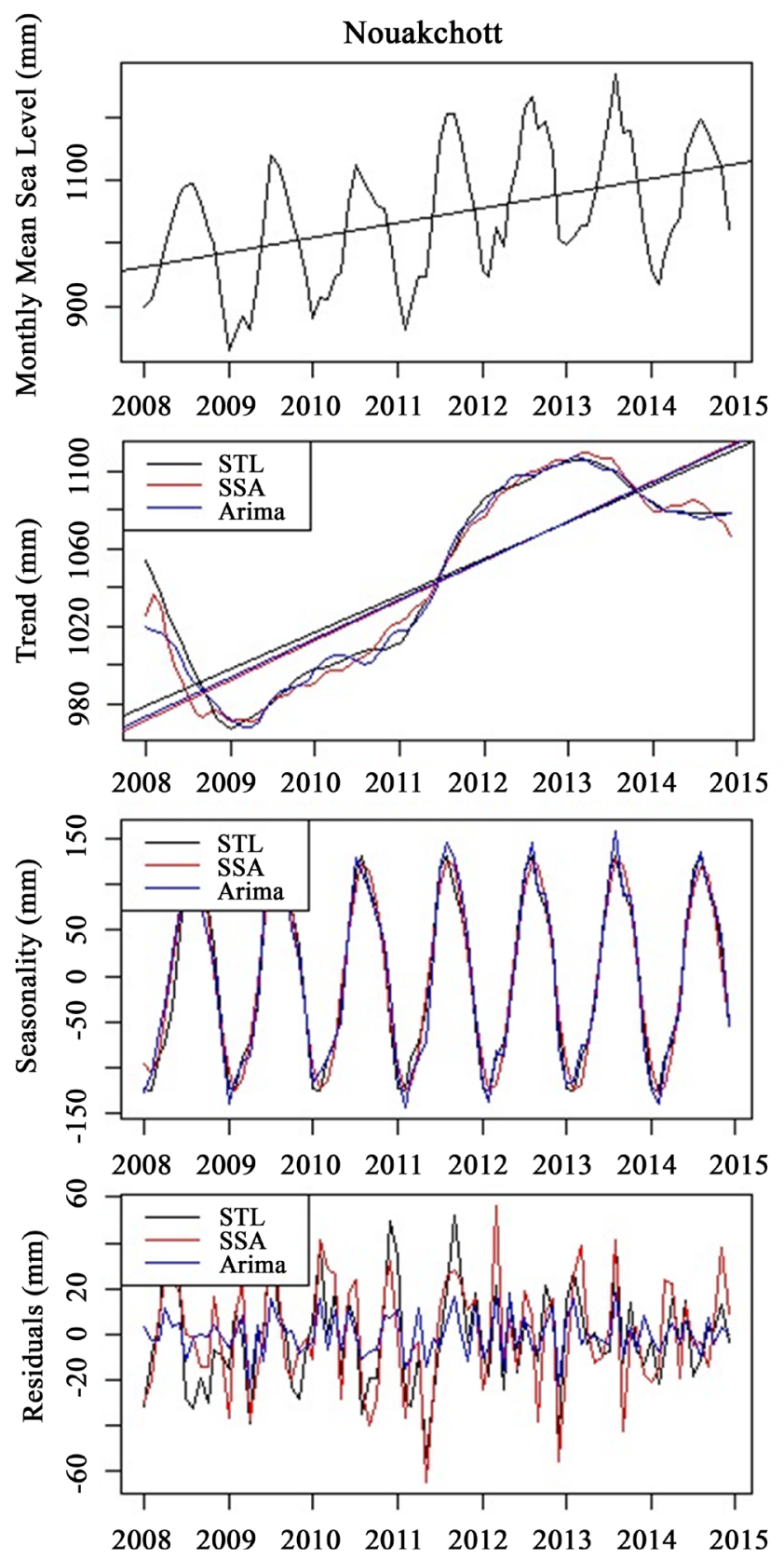

Figure 5. Results of the decomposition of the Nouakchott tide gauge series. In red: SSA, in blue; Arima and in black: STL.

Table 3. Rate of sea level change.

\begin{tabular}{cccccccc}
\hline Station & Périod & $\begin{array}{c}\text { Trend in } \\
\text { the initial } \\
\text { series }\end{array}$ & $\begin{array}{c}\text { STL } \\
(\mathrm{mm} / \text { year })\end{array}$ & $\begin{array}{c}\text { SSA } \\
(\mathrm{mm} / \text { year })\end{array}$ & $\begin{array}{c}\text { ARIMA } \\
(\mathrm{mm} / \text { year })\end{array}$ & $\begin{array}{c}\text { VLM } \\
(\mathrm{mm} / \text { year })\end{array}$ & $\begin{array}{c}\text { Arima corrected } \\
\text { for VLM } \\
\text { (mm/year) }\end{array}$ \\
\hline Dakar & $1993-2018$ & $99.99 \%$ & $1.18 \pm 0.12$ & $1.19 \pm 0.11$ & $1.18 \pm 0.11$ & -0.34 & 1.52 \\
Palmeira & $2001-2018$ & $99.99 \%$ & $4.24 \pm 0.26$ & $3.81 \pm 0.25$ & $4.01 \pm 0.26$ & -0.50 & 4.51 \\
Nouakchott & $2008-2014$ & $99.21 \%$ & $18.87 \pm 1.44$ & $20.46 \pm 1.35$ & $19.83 \pm 1.43$ & -0.25 & 20.08 \\
\hline
\end{tabular}



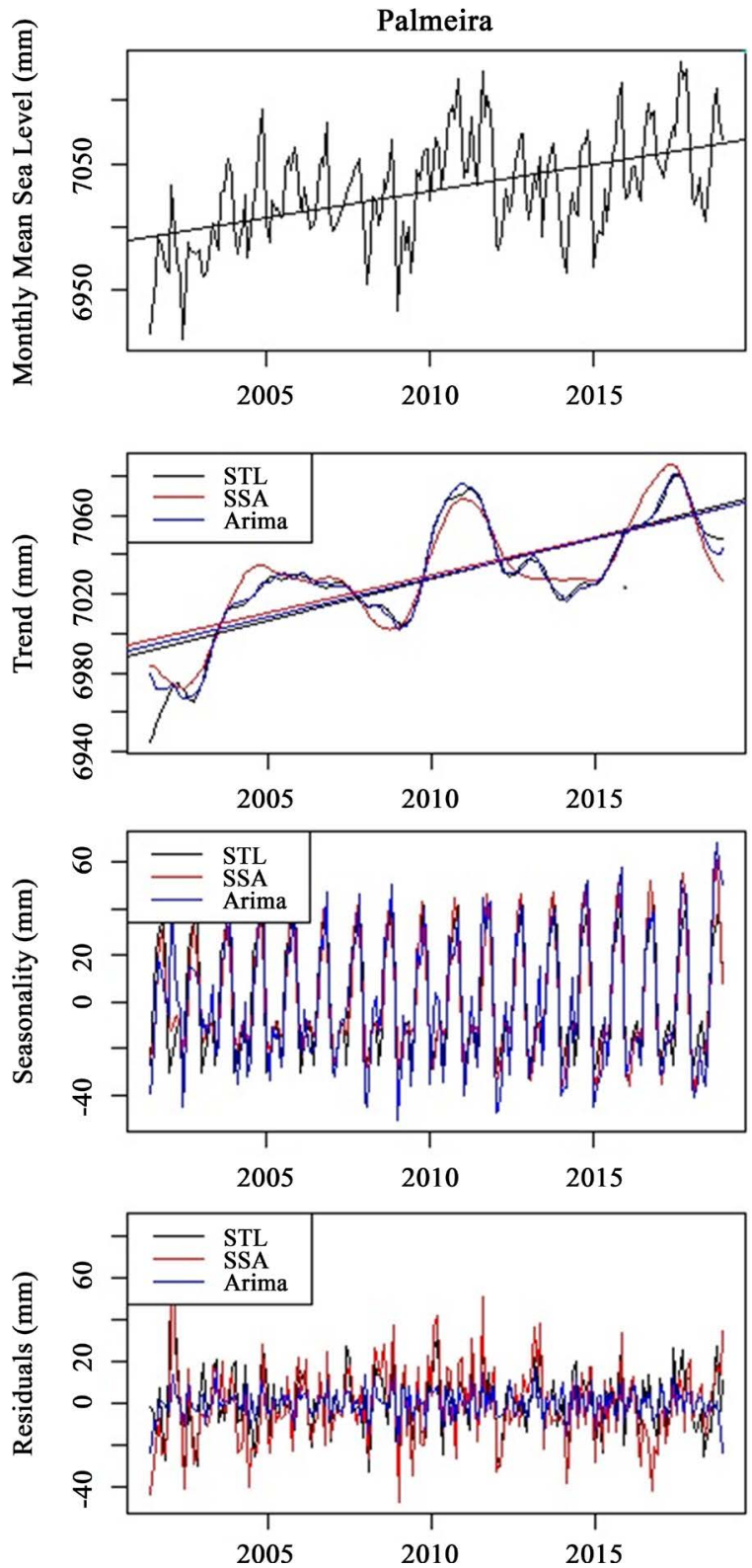

Figure 6. Results of the decomposition of the Palmeria tide gauge series. In red: SSA, in blue; Arima and in black: STL.

\section{Conclusions}

The study of sea level variability is a complex one that requires powerful statistical tools. The use of these techniques enabled us to analyze the trend of variations in sea level at the level of the Dakar, Nouakchott and Palmeira tide stations.

The seasonal Mann-Kendall test is carried out to objectively identify the presence or absence of significant trends in the sea level series. All tide stations show a significant positive trend.

A second analysis was carried out in order to decompose these three series into several components, which can be identified as a non-linear trend, seaso- 
nality and noise components. The results obtained using the three techniques STL, SSA and Arima are very similar. After correcting the vertical movements of the Earth (postglacial rebound), the amplitudes of changes in sea level are: Dakar: $+1.52 \mathrm{~mm} /$ year (1993-2018), Palmeira: $+4.51 \mathrm{~mm} /$ year (2001-2018) and Nouakchott: $20.08 \mathrm{~mm} /$ year (2008-2014). These trends point, all unequivocally, to the same conclusion: sea levels along the West African coast are rising.

Due to the phenomenon of climate change, this study shows the effectiveness of statistical tests in detecting trends in tidal series. The results obtained may seem primary, but it is these trends which, for specialists in climatology, are of paramount importance for the search for correlations between climatic events that the Earth undergoes.

In conclusion and in the light of the results obtained, the following recommendations emerge:

The need to search for forgotten historical measurements in order to extend the data series as far as possible in the past;

The need to conserve the scientific heritage consists of observations of the sea level of the past decades.

\section{Acknowledgements}

Avoid the stilted expression, "One of us (R. B. G.) thanks..." Instead, try "R. B. G. thanks". Do NOT put sponsor acknowledgements in the unnumbered footnote on the first page, but at here.

\section{Conflicts of Interest}

The authors declare no conflicts of interest regarding the publication of this paper.

\section{References}

[1] GIEC (2007) Bilan 2001 des changements climatiques: Les éléments scientifiques. Contribution du Groupe de travail I au troisième rapport d'évaluation du Groupe d'experts intergouvernemental sur l'évolution du climat. https://www.ipcc.ch/site/assets/uploads/2020/02/ar4-wg2-sum-vol-fr.pdf

[2] Lambeck, K., Esat, T.M. and Potter, E.K. (2002) Links between Climate and Sea Levels for the Past Three Million Years. Nature, 419, 199-206. https://doi.org/10.1038/nature01089

[3] Lambeck, K. and Bard, E. (2000) Sea-Level Change along the French Mediterranean Coast since the Time of the Last Glacial Maximum, Earth Planet. Science Letters, 175, 203-222. https://doi.org/10.1016/S0012-821X(99)00289-7

[4] Dunham, A.L. (1954) La révolution industrielle en France (1815-1848). Population, 9, 352-352. https://doi.org/10.2307/1525055

[5] Veltz, P. (2001) La nouvelle révolution industrielle. Revue du MAUSS, 18, 67-70. https://www.cairn.info/revue-du-mauss-2001-2-page-67.htm https://doi.org/10.3917/rdm.018.0067

[6] Douglas, B.C. (2001) Sea Level Change in the Era of the Recording Tide Gauge. In: Douglas, B., et al., Eds., Sea Level Rise: History and Consequences, Academic, San 
Diego, 37-64. https://doi.org/10.1016/S0074-6142(01)80006-1

[7] Université de Colorado (2019) 2018_rel1: Global Mean Sea Level Time Series (Seasonal Signals Removed).

https://sealevel.colorado.edu/data/2020rel1-global-mean-sea-level-seasonal-signalsretained

[8] Cazenave, A., et al. (2018) Global Sea-Level Budget 1993-Present. Earth System Science Data, 10, 1551-1590. https://doi.org/10.5194/essd-10-1551-2018

[9] Nicholls, R.J. and Leatherman, S.P. (1994) The Implications of Accelerated Sea-Level Rise and Developing Countries: A Discussion. Journal of Coastal Research, Spring Issue, 303-323.

[10] Lombard, A. (2005) Les variations actuelles du niveau de la mer: Observations et causes. Thèse de doctorat de l'université Toulouse III, spécialité: Océanographie Spatiale. Thèse soutenue le 25 novembre 2005.

[11] UNESCO (2012) The Global Sea Level Observing System Implementation Plan 2012. Intergovernmental Oceanographic Commission. Technical Series 100, 48 p. https://unesdoc.unesco.org/ark:/48223/pf0000217832

[12] Wöppelmann, G. (2010) Évolution long terme des composantes du niveau de la mer à Dakar (niveau moyen, ondes de marée, résidus météorologiques). Rapport de Stage.

http://refmar.shom.fr/documents/10227/25994/\%C3\%89volution+\%C3\%A0+long+ terme+des+composantes+du+niveau+de+la+mer+\%C3\%A0+Dakar.pdf

[13] Mann, H.B. (1945) Nonparametric Tests against Trend. Econometrica, 13, 245-259. https://doi.org/10.2307/1907187

[14] Kendall, M.G. (1975) Rank Correlation Methods. Griffin, London.

[15] Hirsch, R.M., Slack, J.R. and Smith, R.A. (1982) Techniques of Trend Analysis for Monthly Water Quality Data. Water Resources Research, 18, 107-121. https://doi.org/10.1029/WR018i001p00107

[16] Golyandina, N., Nekrutkin, V. and Zhigljavsky, A. (2001) Analysis of Time Series Structure: SSA and Related Techniques. Chapman \& Hall/CRC, London. https://doi.org/10.1201/9781420035841

[17] Hassani, H. (2007) Singular Spectrum Analysis: Methodology and Comparison. Journal of Data Science, 5, 239-257.

[18] Hassani, H. (2010) A Brief Introduction to Singular Spectrum Analysis. https://www.researchgate.net/profile/Hossein Hassani7/publication/267723014 A Brief Introduction to Singular_Spectrum Analysis/links/548036910cf250f1edbfc8 $\underline{\text { 26.pdf }}$

[19] Harmouche, J., Fourer, D., Flandrin, P., Auger, F. and Borgnat, P. (2015) Une ou deux composantes: La réponse de l'analyse spectrale singulière. Colloque Gretsi 2015, 08-11 septembre 2015. http://perso.ens-lyon.fr/patrick.flandrin/gretsi15JH.pdf

[20] Box, G.E.P. and Jenkins, G.M. (1976) Time Series Analysis: Forecasting and Control. Holden-Day, San Francisco.

[21] Cleveland, S.W. (1979) Robust Locally Weighted Regression and Smoothing Scatterplots. Journal of the American Statistical Association, 74, 829-836. https://doi.org/10.1080/01621459.1979.10481038

[22] Cleveland, W.S. and Delvin, S.J. (1988) Locally Weighted Regression: An Approach to Regression Analysis by Local Fitting. Journal of the American Statistical Association, 83, 596-610. https://doi.org/10.1080/01621459.1988.10478639

[23] Johnson, L., Cooke, B., Ramos, V.H. and Easson, G. (2008) Use of NASA Satellite 
Assets for Predicting Wildfire Potential for Forest Environments in Guatemala. Preliminary Report, University of Mississippi Geoinformatics Center.

https://www.researchgate.net/profile/Greg_Easson/publication/265154859 Use of NASA Satellite Assets for Predicting Wildfire Potential for Forest Environmen ts in Guatemala/links/54466d170cf2d62c304dbd14/Use-of-NASA-Satellite-Assets-f or-Predicting-Wildfire-Potential-for-Forest-Environments-in-Guatemala.pdf

[24] Lu, H., Raupach, M.R. and McVicar, T.R. (2001) Decomposition of Vegetation Cover into Woody and Herbaceous Components Using AVHRR NDVI Time Series. Technical Report 35/01, CSIRO Land and Water, Canberra.

[25] Pohlert, T. (2020) Non-Parametric Trend Tests and Change-Point Detection. https://cran.r-project.org/web/packages/trend/vignettes/trend.pdf

[26] Golyandina, N., Korobeynikov, A., Shlemov, A. and Usevic, K. (2015) Multivariate and 2D Extensions of Singular Spectrum Analysis with the Rssa Package. Journal of Statistical Software, 67, 1-78. https://doi.org/10.18637/jss.v067.i02

[27] Peltier, W.R., Argus, D.F. and Drummond, R. (2015) Space Geodesy Constrains Ice-Age Terminal Deglaciation: The Global ICE-6G_C (VM5a) Model. Journal of Geophysical Research-Solid Earth, 120, 450-487.

https://doi.org/10.1002/2014JB011176 